\title{
A COMPARATIVE SUITABILITY STUDY BETWEEN CLASSIFICATION SYSTEMS FOR BIM IN HERITAGE
}

\author{
NOHA SALEEB ${ }^{1}$, MOHAMED MARZOUK $^{2} \&$ USAMA ATTEYA $^{2}$ \\ ${ }^{1}$ Middlesex University, United Kingdom \\ ${ }^{2}$ Cairo University, Egypt
}

\begin{abstract}
The research outlined in this paper is part of a collaborative fund to propose an innovative classification framework for restoration of historical/cultural heritage assets. Most of the previous research/applications in applying BIM to Heritage have focused on the physical or geometric reporting of assets. This typically involves laser scanning for creating as-built models and recording asset components, for operations and maintenance. However to efficiently identify/record general asset component requirements, standardised classification systems must be used which categorise different components, their characteristics, attributes, and maintenance requirements. Furthermore as will be demonstrated, current database, knowledge and classification systems available for new builds might not be suitable to categorise components in historical buildings, which differ according to historical eras and architectural periods, hence might render their restoration process inefficient. There is currently no research dedicated towards investigating appropriate classification systems to be used for heritage buildings. This paper provides a comparative study between current international classification systems within the construction industry, and investigates their suitability for heritage buildings. This includes CI/SFB, CAW, SFG20, Omniclass, Uniclass versions etc. Properties of suitability will also be investigated e.g. object types, hierarchy of tables/schedules, depth levels and appropriateness for different architectural styles and parametric geometries (e.g. origin, material, allowed stresses, proportions etc.). This study provides evidence for the lack of appropriate classification systems for Heritage and provides recommendations for a taxonomical representation for suitable classification systems of Heritage assets from different historical and architectural periods. This includes information descriptors of hierarchical classes, historical, social and technological context, allowing usage of standardised Heritage BIM data for documentation, operations, maintenance and restoration management, and also allowing searching for similarities/differences between different buildings in the global heritage domain, replacement components and comparing artefacts, which might impact historical significance.

Keywords: Building information modelling; CAW; CI/SFB; classifications systems; heritage buildings; omniclass; SFG20; typology; uniclass.
\end{abstract}

\section{INTRODUCTION}

In the world of construction, no two buildings or assets are identical. It is hence imperative to be able to differentiate between assets by classifying their different components to conduct comparative studies or relationships between them, or allow constructing, maintaining and preserving them based on these constituent components they comprise of. This becomes even more relevant when considering historical or heritage buildings, which belong to different architectural styles and historical eras, are built in different unique methods and contain different building elements and components. A heritage building can be defined as a building of one or more premises or artefacts which require conservation and/or preservation for historical, architectural, aesthetic, cultural, environmental and/or ecological purposes [1]. The need to renovate refurbish, and maintain them dictates accurate recording of their constituent building elements and blocks and their detailed characteristics to be able to replace or conserve them in the optimum methods possible. 
Classification can be defined as "The act or process of dividing things into groups according to their type" [2]. However, current available classification systems used in the construction industry worldwide are predominantly used for classifying new building components, as will be explained subsequently, that are either under construction or have been erected in the last few decades, and hence are not classified as heritage. On a related front, a typology can refer to the study and documentation of buildings or elements, which have similarities in their form. Many different variations can be found, each with different characteristics as a result of local materials, habits, age and technology [3], or even basic form, site configuration, and scale, but not their specific architectural style, or precise use. They can even be related to the era, the culture and the environment in which they arise $[4,5]$. Based on the above definitions, it is logical to endeavour to create a classification typology system for categorising heritage building components that would encompass all the above characteristics, both graphical and non-graphical to enable the following within the realms of using Building Information Modelling (BIM) tools, technologies, workflows and processes:

- Recording and codifying the elements/components inside 3D models of the building for archiving purposes and identification of architectural style and purpose.

- The ability to maintain the components based on their characteristics identified in the classification system.

- The ability to replace the components based on identifying other available components that are the same.

The subsequent section provides a comparative study between current classification systems used widely in the construction industry.

\section{CLASSIFICATION SYSTEMS IN THE CONSTRUCTION INDUSTRY}

The classifications systems, which are currently in abundant usage in the construction industry, that will be discussed in this paper are

- CI/SFB - Construction Index/Samarbetskommitten for Byggnadsfragor

- CAWS - Common Arrangement of Work Sections

- SFG20 - Standard Maintenance Specification

- Omniclass

- Uniclass

- Uniclass 2

- Uniclass 2015

- NRM - New Rules of Measurement

The following Table 1 shows a comparison between some of their characteristics, followed by an analysis of their respective advantages and disadvantages and their current suitability for specifying heritage-building components.

\section{$2.1 \mathrm{CI} / \mathrm{SFB}$}

This classification system was produced by the Swedish Committee for Building Investigation based on the BS1192-5:1998 British Standard for Construction Drawing Practice. It can be 
Table 1: Characteristics of classification systems used in the construction industry.

\begin{tabular}{|c|c|c|c|c|c|c|c|c|}
\hline & CI/SFB & CAWS & SFG20 & OmniClass & UniClass & Uniclass2 & \begin{tabular}{|l|} 
Uniclass \\
2015 \\
\end{tabular} & NRM \\
\hline $\begin{array}{l}\text { Date of } \\
\text { creation }\end{array}$ & 1959 & 1987 & \begin{tabular}{|l|}
1990 books, \\
2000 cd format \\
2012 web \\
library
\end{tabular} & 2006 & 1997 & 2013 & 2015 & $\begin{array}{l}\text { NRM1 }=2009 \\
\text { NRM2 }=2012 \\
\text { NRM3 }=2014\end{array}$ \\
\hline Country & UK & UK & UK & North America & UK & UK & UK & UK \\
\hline $\begin{array}{l}\text { Organization } \\
\text { / origin }\end{array}$ & $\begin{array}{l}\text { SfB Agency } \\
\text { UK }\end{array}$ & CPIC & BESA & CSI and CSC & $\begin{array}{l}\text { CPIC and } \\
\text { NBS }\end{array}$ & CPIC and NBS & \begin{tabular}{|l|} 
CPIC and \\
NBS
\end{tabular} & RICS \\
\hline $\begin{array}{l}\text { Currently In } \\
\text { Use? }\end{array}$ & Yes & Yes & Yes & Yes & No & No & Yes & Yes \\
\hline $\begin{array}{l}\text { Purpose and } \\
\text { properties }\end{array}$ & \begin{tabular}{|l|} 
Arrangement \\
of project \\
information \\
including \\
sets of \\
drawings, \\
specification \\
s and bills of \\
quantities. \\
\end{tabular} & \begin{tabular}{|l|} 
Defining an \\
efficient and \\
acceptable \\
arrangement \\
for \\
specifications \\
and Bills of \\
Quantities for \\
building \\
projects
\end{tabular} & $\begin{array}{l}\text { Standard } \\
\text { Maintenance } \\
\text { Specification } \\
\text { for Building } \\
\text { Services and } \\
\text { manufacturers } \\
\\
\end{array}$ & \begin{tabular}{|l|} 
Organization, \\
sorting and \\
retrieval of \\
product \\
information \\
for all objects \\
in the built \\
environment \\
in the project \\
life cycle.
\end{tabular} & $\begin{array}{l}\text { For all aspects } \\
\text { of the design } \\
\text { and } \\
\text { construction } \\
\text { process. }\end{array}$ & \begin{tabular}{|l|} 
Development on \\
Uniclass because \\
Uniclass 1.4 \\
(latest before \\
uniclass2) was \\
criticized for not \\
being unified, \\
for \\
inconsistencies \\
between \\
labelling and \\
depth of tables, \\
for poor \\
integration \\
of civil \\
engineering and \\
building works \\
and for being \\
paper-based \\
system.
\end{tabular} & \begin{tabular}{|l|} 
Feedback \\
received \\
regarding Uni- \\
class 2, \\
further \\
changes were \\
made, and a \\
new \\
version, Unicl \\
ass2015 releas \\
ed. The most \\
significant \\
change was \\
the removal of \\
the Work \\
Results table. \\
\end{tabular} & $\begin{array}{l}\text { Provides a } \\
\text { standard set } \\
\text { of measure- } \\
\text { ment rules } \\
\text { for estimating, } \\
\text { cost } \\
\text { planning, } \\
\text { procurement } \\
\text { and whole-life } \\
\text { costing for } \\
\text { construction } \\
\text { projects in the } \\
\text { UK. }\end{array}$ \\
\hline $\begin{array}{l}\text { Types of } \\
\text { components }\end{array}$ & faceted & faceted & faceted & faceted & faceted & faceted & faceted & $\begin{array}{l}\text { faceted and } \\
\text { non faceted }\end{array}$ \\
\hline $\begin{array}{l}\text { No. of tables } \\
\text { / schedules }\end{array}$ & 5 tables & $\begin{array}{l}24 \text { categories / } \\
>300 \text { sections }\end{array}$ & $\begin{array}{l}16 \text { tables / } \\
>400 \text { schedules }\end{array}$ & 15 tables & 16 tables & 8 Tables & 11 tables & $\begin{array}{l}\text { NRM1 - } 13 \\
\text { categories } \\
\text { NRM2 - } 41\end{array}$ \\
\hline $\begin{array}{l}\text { Levels of } \\
\text { depth }\end{array}$ & - & 3 & 2 & 2 to 8 & 2 to 7 & 2 to 7 & 4 or 5 & 4 or 5 \\
\hline
\end{tabular}

considered as a library classification with only five tables about the physical environment, architectural elements, forms materials and activities. However, it was cirticised for lacking on specifications and pricing for mechanical/electrical services, not reflecting changes in the industry, e.g. new building types, new performance issues, and its notations being difficult to understand and computerise. These limitations led to developing newer approaches to classification systems internationally [6,7].

\subsection{CAWS}

This classification system was developed by the Construction Project Information Committee (CPIC) to improve quality of information, which was seen lacking in its predecessor $\mathrm{CI} / \mathrm{Sfb}$. It contains more than 300 sections of components and was used for standardisation and coordination between bills of quantities and specifications. However, one of its drawbacks is that the elements are not ordered elementally - hence can be seen as inappropriate for object naming inside 3D BIM models, and the system is not well suited for computerised applications. Also, some categories were considered lacking in it e.g. civil engineering and process engineering alongside architecture and landscape, which were better accommodated in the subsequent Uniclass system enabling the description of systems in performance terms, and more suitability to facilities management $[8,9]$. 


\subsection{SFG20}

SFG20 was mainly developed by the Building and Engineering Services Association (B\&ES) as a Library of maintenance specifications for building engineering services. It is one of the currently widely used classification systems mainly for maintenance and by contractors and manufacturers. One of its advantages is that it is web-based (via a subscription) and contains over 400 schedules, which are compliant with current standards [10]. The recent SFG20 development has aligned the software with the RICS New Rules of Measurement hence enabling streamlining with budgeting and maintenance asset registers [11]. However, SFG20 is not currently the most popular classification system for inclusion at early design stages for specification of objects inside 3D BIM models, unlike Omniclass and Uniclass versions explained below, maybe due to its focus on services and maintenance systems as opposed to architectural system components. Also as will be explained consequently, the classification does not extend to include essential categorisations related to heritage e.g. historical period etc.

\subsection{Omniclass}

Omniclass is the classification currently in the construction industry in US consisting of 15 tables based on ISO 12006-2 (Organisation of Information about building Works - Framework for Classification), and incorporated inside a number of 3D BIM authoring software e.g. Revit. While widely utilised, some disadvantages have been identified in the classification system e.g. Not all the scopes of the tables incorporate Architecture, Civil and Services engineering. The depth of levels of the tables varies from two to eight levels of hierarchy, which causes inconsistency in the level of description of the components. Furthermore, the objects' description inside the tables is sometimes for groups of objects and sometimes for individual objects, which can cause discrepancy in specification. Some difficulties in the mapping between the tables and some deficiencies in them have also been identified e.g. the Work Results Table has deficiencies serving the entire project timeline and all procurement routes, and hence supporting BIM $[12,13]$. The above disadvantages in addition to requirements for heritage components render it necessary to develop a more suitable classification system for heritage.

\subsection{Uniclass}

The Uniclass classification systems were developed under the sponsorship of the CPIC and NBS, UK. There are three versions of the classification system, but the one currently used is Uniclass 2015 and is it automated and incorporated inside the UK Digital Plan of Work (DPoW). Uniclass v1.4 was developed based on the CAWS, EPIC, CI/Sfb classification systems and also aligned to ISO 12006-2. However, like Omniclass, not all tables focused on all of architectural, civil and process engineering components. It varied in the depth of its levels between 2 and 7, and objects were again sometimes organised in groups and sometimes individually. However, two other major disadvantages were that the tables were not aligned together (individually created) and the coding of the objects was sometimes numeric and sometimes alphanumeric causing confusion in classifying the objects. The misalignment and coding errors were then rectified in the next version Uniclass 2, so that all eight tables now had hierarchical relationships between them. Nevertheless, the classification system was not 
completed, was predominantly architectural and was taken over by NBS to redevelop into Uniclass 2015 in tandem with the web-based Digital Plan of Work. The latest Uniclass 2015 with its nine tables (and two under consultation) is currently used in the construction industry to support classification of buildings, engineering, landscape, infrastructure and is compliant with ISO 12006-2, mapped to NRM1, and has developed relationships and hierarchical levels between its tables [14-16]. However, as will be described subsequently, there are required attributes for classifying heritage components, which are non-existent in this classification system.

\subsection{NRM}

The New Rules of Measurement created by the RICS are considered by many professionals in the construction industry as a classification system; however, they are strict systems for rules to aid in categorisation of elements and components and their attributes/characteristics/ measuring units to calculate bills of quantities. Hence they should not be used for classifying the objects but measuring them. The NRM consists of three parts developed after a predecessor SMM7 (Common Arrangement of Work Sections):

- NRM 1 for initial cost estimating and planning for capital building works, costs and investment

- NRM 2 for detailed measurement of building works. This is a set of detailed measurement rules enabling work to be bought either through bills of quantities or schedules of rates for capital or maintenance projects.

- NRM 3 for cost estimating and cost planning for building maintenance works and lifecycle replacement works.

NRM 1 contains 13 categories of elements, NRM 2 contains 41 detailed categories, and NRM 3 contains 10 main categorisations. However, an asset component cannot be specified with the same depth of hierarchy of tables as using other classification systems such as Omniclass and Uniclass [17, 18].

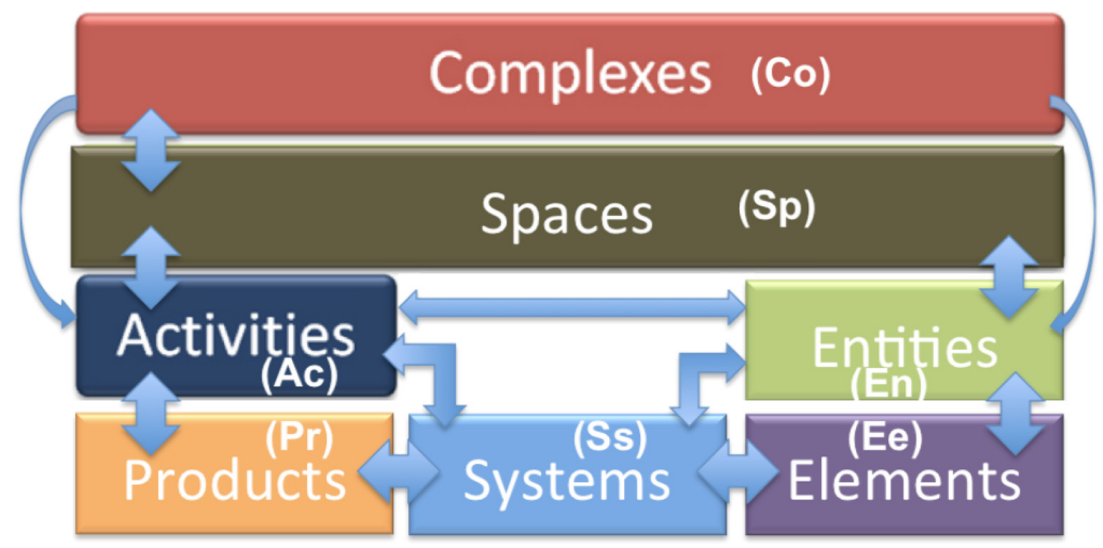

Figure 1: Tables and their relationships used in Uniclass 2015. 


\subsection{Current example of classification}

The current method of classifying an object denotes giving it a code consisting of four or five pairs of characters. The first pair signifies which main table is being used and this employs letters. For example, Figure 1 below shows the tables which classify objects in Uniclass 2015.

The next four pairs of the classification code represent groups, sub-groups and sections of objects inside this table. The combinations of selections can allow for inclusion of thousands of objects.

For example:

- Ss: Systems

- Ss-30 : Roof, floor and paving systems

- Ss-30-10: Pitched, arched and domed roof structure systems

- Ss-30-10-30: Framed roof structure systems

- Ss-30-10-30-25: Heavy steel pitched roof framing systems

However, current classification systems, including Uniclass 2015 naming conventions and scope are not specifically relevant to Heritage [19], as there is no inclusion for attributes related to heritage characteristics e.g. architectural style, geometric characteristics and ratio, condition, construction method, cultural value, in addition to material, colour, reflectance characteristics [20] that would help replace or maintain/renovate an object accurately.

\section{CREATING A HERITAGE CLASSIFICATION SYSTEM}

According to Gelder [21], there are seven requirements for creating a classification system, which were abided by on development of the Uniclass suite of classification systems.

- Digital, quick to use, and free. An online digital format which would allow rapid searching across all the tables simultaneously

- Unified. The tables are not produced independently and have associations between them. They should be congruent with similar terminology, sequencing, grouping and coding. There should also be one classification mode per table.

- Cross-sector, i.e. benefitting many disciplines in the industry (e.g. buildings, infrastructure), sector-neutral, cross-role and cross-purpose

- Full asset lifecycle (e.g. development, use, FM, demolition). This includes an object hierarchy across all project phases and timeline

- Consider legacy classification systems

- Compliant with ISO 12006-2:2015

- Integration with barcoding developed by manufacturers for products.

Classification arranges the broadest classes at the highest levels, root levels, and then the more specific classes are arranged at the lower levels. These subclasses are specialisations of their superclass and any superclass is a generalisation of its subclasses [22], i.e. properties of a super-class are general and properties of subclasses are specific. The above requirements for creating a classification system can be suitable for creating a classification system for Heritage components to holistically apply to all asset functions and the whole lifecycle. However, Afsari and Eastman [23] further elaborate that there are four basic features for a 
classification system. The authors of this paper argue that these can be used differently between classification systems for new builds and heritage builds, as follows:

- The purpose and properties of the objects included in the classification: As previously elaborated there are essential characteristics related to classifying heritage objects which should be included that are not currently used e.g. architectural style, geometric characteristics and ratio, condition, construction method, cultural value, material, colour, reflectance characteristics.

- The framework of the system: This plays a significant role as an information centre through the lifecycle of a project. The object tables' structures and relationships currently used are those within the classification systems described at the beginning of this paper. These require to be adjusted to suit heritage asset functionalities and irregularities.

- The grouping principles within the system: There are two strategies for grouping. The first is Direct (hierarchical) grouping where classes of objects are identified through a combination of properties; however, new objects cannot be accommodated without creating new revisions of the classification. This type of grouping is used for many of the current construction classification systems [23]. The second grouping type is the Combinatory (faceted) grouping where classes of objects can be identified using multiple sets of attributes. A facet acts as a set of similar properties such as functions to enable categorising objects accordingly. In a faceted classification, new objects can be classified by a combination of these concepts [24]. This is suitable for a heritage classification system as new found and unique objects may need to entered into the system constantly and which may be categorised using multiple attributes related to function, social value, environmental context etc., which are not conventional attributes in current classification systems.

- Organisation and taxonomies of tables: Examples of sectioning criteria are compositional attributes and functional attributes. Compositional attributes include geometrical shape or construction material and examples of functional attributes are load bearing or climate separating [25]. If each node in the hierarchy indicates a class based on only one criterion, the classification is known as clean and if multiple criteria are used, the classification is mixed. Jorgensen [22] argues that usually objects belong to only one node in taxonomy, but sometimes can belong to multiple nodes, where one of the nodes is primary class and the other classes are secondary. Within heritage context there needs to be further investigation whether a suitable structure would be clean or mixed using multiple criteria for classification.

\section{CONCLUSION}

This paper provided a comparative analysis between different classification systems currently used within the construction industry for classifying objects and components in new and existing assets for the purposes of BIM processes and workflows. The study further highlighted the shortcomings of current classification systems and the need for developing more specialised classification systems suitable for heritage buildings. Four main requirements for development have been identified, in addition to further attributes essential for defining heritage components, which include both geometric and non-geometric information. This paper is part of an ongoing research to develop a classification system suitable for heritage. Hence, a challenge remains to be investigated, whether a unified new heritage classification system can be viable for different heritage/historic periods and architectural styles, or whether specialised classification systems are required for different periods. 


\section{REFERENCES}

[1] Bhawan, N., Conservation of heritage buildings - a guide, Directorate General Central Public Works Department : New Delhi, pp. 1-2, 2013.

[2] Designing Buildings Wiki. BIM classification, available at: https://www.designingbuildings.co.uk/wiki/BIM_classification. (accessed 5 March 2017).

[3] Firley, E. \& Stahl, C., The urban housing handbook. Chichester/Hoboken: Wiley, pp. 1-9, 2009.

[4] Caniggia, G. \& Maffei, G., Architectural composition and building typology: interpreting basic building. Aliniea Editrice, Florence, 2001.

[5] Scheer, B.C., The evolution of urban form: typology for planners and architects. American Planning Association, 2010.

[6] Gelder, J., Classification, available at: http://www.cpic.org.uk/wp-content/uploads/2013/ 06/classification_v1.2.pdf. (Accessed on 6 March 2017).

[7] Ray-Jones A., Classification by CI/SfB. Journal of Building Research and Practice, 2(6), pp. 314-316, 1974.

[8] Designing Buildings Wiki, Common arrangement of work sections, available at: https:// www.designingbuildings.co.uk/wiki/Common_Arrangement_of_Work_Sections. (Accessed 6 March, 2017).

[9] Finch, R., Co-ordinating common arrangement, uniclass, NBS and rules of measurement, available at: https://www.thenbs.com/knowledge/co-ordinating-common-arrangementuniclass-nbs-and-rules-of-measurement. (Accessed 6 March 2017).

[10] Ralph, M., The standard for maintenance, available at: http://hfc.org.uk/wp-content/ uploads/2016-06-MikeRalph.pdf. (Accessed 6 March, 2017).

[11] FMWorld, Maintaining standards, available at: http://www.fm-world.co.uk/features/ feature-articles/maintaining-standards/. (Accessed 6 March 2017).

[12] 4BT, OMNICLASS vs. UNICLASS / UNICLASS2 - BIM Ontology, available at: https:// jobordercontracting.org/2013/06/06/omniclass-vs-uniclass-uniclass2-bim-ontology/. (Accessed 1 March, 2017).

[13] Gelder, J., Omniclass: a critique, available at: https://www.thenbs.com/knowledge/ omniclass-a-critique. (accessed 2 March 2017).

[14] NBS, Uniclass 2015 - an update, available at: https://www.thenbs.com/knowledge/ uniclass-2015-an-update. (accessed 12 March 2017).

[15] CPIx, Uniclass2, available at: http://www.cpic.org.uk/uniclass/. (accessed 12 March 2017).

[16] BIM Taskgroup, Uniclass 2: Demystified, available at: http://www.bimtaskgroup.org/ wp-content/uploads/2013/06/BIM-Task-Group-Newsletter-21st-Edition.pdf. (accessed 12 March 2017).

[17] RICS, RICS NRM: new rules of measurement, available at: https://www.rics.org/uk/ knowledge/professional-guidance/guidance-notes/new-rules-of-measurement-orderof-cost-estimating-and-elemental-cost-planning/. (accessed 12 March 2017).

[18] Earl, S. The RICS' new rules of measurement, available at: http://www.building.co.uk/ the-rics-new-rules-of-measurement/5033890.article. (accessed 12 March 2017).

[19] Bryan, P. BIM for heritage: developing an historic building information model. Presentation, Historic England, UK, 2017.

[20] Andreetto, M., Brusco, N. \& Cortelazzo, G.M., Automatic 3D modeling of textured cultural heritage objects. IEEE Transactions on Image Processing, 13(3), pp. 354-369, 2004.

https://doi.org/10.1109/tip.2003.821351 
[21] Crawford, R.H. \& Stephan, A. (eds.), Living and learning: research for a better built environment. 49th International Conference of the Architectural Science Association 2015, The Architectural Science Association and The University of Melbourne, pp. 287-297, 2015.

[22] Jorgensen, K. A., Classification of building object types- misconceptions, challenges and opportunities. Proceedings of CIB W78-W102 International Conference. Sophia Antipolis, France, 26-28 October 2011.

[23] Afsari, K. \& Eastman, C.M., A comparison of construction classification systems used for classifying building product models. In 52nd ASC Annual International Conference Proceedings, 2016.

[24] Ekholm, A., A conceptual framework for classification of construction works. ITcon (Electronic Journal of Information Technology in Construction), 1, pp. 1-25, 1996.

[25] Ekholm, A., \& Häggström, L., Building classification for BIM - Reconsidering the framework. Proceedings of the CIB W078-W102: 2011 Joint International Conference. Sophia Antipolis, France, 26-28 October, 2011. Retrieved from http://2011-cibw078w102.cstb.fr/papers/Paper-20.pdf 